\title{
19th ANNUAL MEETING
}

\author{
of the \\ European Society for Paediatric Endocrinology
}

\author{
August 31-September 3, 1980 \\ Bergamo, Italy
}

\section{PRESENTED}

D. GENDREL* M.C. FEINSTEIN* J. INGRAND,

1 J. GRENIER; P. CANLORBE, and J.C. JOB. HOP. Saint-Vincent de Paul, Paris, France. High radioimmunoassayable plasma TSH in newborns with normal thyroid function and in their mothers.

Among 75734 newborns submitted to TSH screening, 22 had documented hypothyroidism and 6 were found at the time of recall ( $3 \mathrm{~d}-4 \mathrm{th}$ week) to have persistently high plasma TSH levels (40 to $300 \mu \mathrm{U} / \mathrm{ml}$ ), normal plasma T4 $(9.1$ to $12.3 \mu \mathrm{g} / \mathrm{dl})$ and $\mathrm{T} 3(1.5$ to $2.6 \mathrm{ng} / \mathrm{ml})$, normal thyroid scintiscan and urine iodine. 4 of them treated with T4 increased their plasma $T 4$ in the hyperthyroid range without decreasing TSH, and their TSH did not rise when this treatment was stopped. In all 6, plasma TSH decreased spontaneously to normal at 3-8 months. TSH was normal in fathers but persistently elevated in mothers ( 52 to $460 \mu \mathrm{U} / \mathrm{ml}$ ) contrasting with normal T4, T3, scintiscan, thyroid iodine uptake and response to exogenous TSH. No thyroid autoantibodies were found. In vitro studies demonstrated in plasma of infants and mothers lack of antiTSH antibodies, abnormal TSH dilution curves, and correction of the apparently high TSH levels by addition of normal rabbit serum ( 3 and $25 \mathrm{nl}$ incubate). These data suggest the placental transmission of a maternal plasma substance blocking antiTSH rabbit $\gamma$ globulin, and must lead to avoid inadequate diagnosis and therapy in neonates.

P.CZERNICHOW, J.L.VANDALEN ${ }^{\star}$, and G.HENNEN ${ }^{\pi}$

2 Service d'endocrinologie (Pr.R.Rappaport) Hôpital des Enfants Malades, PARIS, France et $*$ Section d'endocrinologie, Institut de Médecine de LIEGE, BELGIUM. Passive materno-fetal transfer of a material interfering in the TSH radioimmunoassay : a cause to transitory neonatal hyperthyrotropenemia.

Through our screening program for hypothyroidism 16 babies were detected with high TSH at day $5(83.5 \pm 40 \mathrm{uu} / \mathrm{ml}$ Blood). They were euthyroid with normal thyroid scintigram (123I) and normal T4 and T3. Plasma radioimmunoassayable TSH (RIA-TSH) gradually decreased to reach normal values at the end of the second month. Mothers were euthyroid with no past history of thyroid diseases and no medication taken during pregnancy. Plasma RIA-TSH was elevated, remained high during 2 months post partum.

Although this material exhibited a perfect parralelism in the TSH-RIA with the standard TSH it has a molecular weight of 150.000 (sepharose $6 \mathrm{~B}$ chromatography). It is retained by Prot A sepharose column wich indicates that it is an immunoglobulin. Preliminary data show that it binds $125 \mathrm{I}^{-\mathrm{TSH}}$ and rabbit $125_{\mathrm{I}}$-IgG. In conclusion

High molecular weight TSH like material is passively transfered from mother to fetus leading to false high TSH values in the neonates. Time decay in the neonates, molecular weight and biochemi. cal propertie seems to indicate that it is an immunoglobulin, probably secreted during pregnancy.
T.TORRESANI*, ELISABETH SCHUSTER*, RUTH ILLIG

3 Dept. of Pediatrics, University of Zurich, Switzerland In vitro micro-bioassay of plasma LH suitable for serial determinations in children.

By modification of an in vitro rat bioassay (1), we have developed a micro-method which allows simultaneous incubation of 12 unknown samples each at 3 dose levels, using $1-10 \mu \mid$ of unextracted plasma. Testes of 8 to 10 weeks old rats are digested with collagenase; the separated interstitial cells are suspended in Medium 199 and incubated under $\mathrm{O}_{2} / \mathrm{CO}_{2}(95 / 5 \%)$ at $37^{\circ} \mathrm{C}$ for 3 hours. Testosterone $(T)$ is measured by an 21 hours-RIA using 125-iodine labelled tracer. T production after incubation with $25 \mathrm{ng}$ of the standard pituitary extract hLH LER 907 is about 8 times the basal value produced in the absence of gonadotropins (range of standard curve 0.5 $25 \mathrm{ngLH}$; sensitivity $0.5 \mathrm{ngLH}$; between-assay variation at $25 \mathrm{ng}$ level: $10 \%)$. LH values in human plosma determined with our bioassay are higher than RIA values. Our results show that Bio/RIA ratios vary at different RIA LH levels, the lowest so far measured being 2.0. The high bioassay values associated with low immunological $\mathrm{LH}$ values observed in some of our patients may help to clarify unexplained discrepancies between RIA results and clinical findings.

(1) DUFAU et al, J.Clin Endocrinol Metab 42:958,1976

Supported by the Swiss National Science Foundation Grant No. 3.901.077

H.L. LENKO*, U. LANG*, M.L. AUBERT, L. PAUNIER* and 4 P.C. SIZONENKO. Clinical Biology of Growth and Reproduction, Department of Pediatrics and Genetics, University of Geneva School of Medicine, Switzerland. Melatonin in plasma and urine before and during puberty.

Melatonin has been suggested to play a role during puberty. A recent study showed that daytime serum melatonin levels, measured by GCMS, are significantly higher in prepubertal than pubertal boys. Daytime plasma melatonin levels measured by RIA in 116 children before and during puberty were similar during the different pubertal stages. The mean plasma melatonin, $\mathrm{pg} / \mathrm{ml}+\mathrm{SEM}$ were:

\begin{tabular}{lcccccccc}
\hline $\begin{array}{l}\text { Puberty } \\
\text { stage }\end{array}$ & M 1 & P yrs & M 10 yrs & P 2 & P 3 & P 4 & P 5 \\
& F 7 yrs & F 8 yrs & & & & & & \\
\hline boys & $9.0 \pm 1.4$ & $5.8 \pm 1.0$ & $5.2 \pm 1.7$ & $7.0 \pm 1.4$ & $8.5 \pm 0.9$ & $4.7 \pm 1.2$ \\
girls & $9.3 \pm 2.3$ & $7.2 \pm 2.0$ & $8.3 \pm 3.4$ & $11.3 \pm 3.7$ & $8.0 \pm 2.5$ & $5.1 \pm 0.6$ \\
\hline
\end{tabular}

Both plasma and urine melatonin levels showed a circadian rhythm with higher levels at night. To detect a possible difference in night melatonin levels we measured the 24 hour urinary melatonin by RIA in 43 children of various pubertal stages. We found a wide individual variation from $6.4 \mathrm{ng} / 24 \mathrm{~h} / \mathrm{m}^{2}$ to $161.0 \mathrm{ng} / 24 \mathrm{~h} / \mathrm{m}^{2}$ but no significant changes between different pubertal stages (meant $\mathrm{SEM}, \mathrm{ng} / 24 \mathrm{~h} / \mathrm{m}^{2}$, for P1 $42.1+6.5$, P2 $49.3+13.6$, P3-5 $30.5+6.6$ ). Thus, our results are in contradiction with the previously observed change of melatonin levels in boys before and during puberty. 